\title{
A New Counterfeiting Approach: Computer Security Evaluation Of Fuel Rationing System
}

\author{
Al-Shawabkeh Mahmoud ${ }^{1}$ Xichun $\mathrm{Li}^{2}$ \\ 1. National Defense University of Malaysia \\ 2. Guangxi Normal University for Nationalities, Chongzuo City, Guangxi Province, China \\ mahmoud.alshawabkeh@gmail.com,291495244@qq.com
} Keywords: Computer Security,
Assessment, Fuel Rationing System.

Counterfeiting, Risk

\begin{abstract}
Engineering, Car Industry, Electronics, Software Suppliers, and Banks depending on the technology and highly sensitive information for their success, they have to invest on espionage and counterfeiting to keep a head of their competitors. Fuel rationing was introduced in 1941 as part of the war effort and it was not removed until 1950. In this period the fuel was banned for private vehicles and heavy penalties applied if it was discovered. When the ration was removed in 1950 there was a widespread black market, and extensive forgery of ration coupons. Longer term secure rationing is inevitable and there has been no investment in the approach to be used. It is clear that a paper coupon book will be widely counterfeited in its current form and a new approach is required with either a stronger coupon design or a different method. This research plan and develop a secure fuel rationing system. Finding confirms the need of return of invest on the fuel chain contingency system provide a model to describe how the rationing system resist counterfeiting, corruptions, hacking and cyber-attacks. Furthermore, the research state the main three effective attacks and how the proposed rationing systems deal with them.
\end{abstract}

\section{Introduction}

Several studies conducted to address the industrial espionage problem, the recent survey in United Kingdom in year 2014 states that $55 \%$ of United Kingdom large companies and $14 \%$ of small companies encountered confidential information leakage by internal employees [1]. However, the importance of understanding the effect of counterfeiting on business and economy is summarized in the Pie chart showing in Figure 1. [2]. The process of detecting counterfeiting items is complicated and hard to implement. that's confirms the research gap this report tries to address.

\section{Counterfeiting Deterrence System (CDS)}

In most countries reproduction of banknotes is considered a crime, in some countries for a specific reason, the banknotes reproduction is permitted. Image editors applications such as adobe Photoshop reject printing banknotes [3]. Reason is the Central Bank Counterfeit Deterrence Group (CBCDG), developed a banknote code detection, embedded in the adobe applications. The code works by detecting the digital watermark embedded in the banknotes.

\subsection{Counterfeiting Tokens and Coupons}

Token means a ticket, coupon, coin, disc, slug, or any other thing that is evidence of the right of an individual to enter, leave, ride on, or pass through or over anything or place for which a fee is charged, including a building, ground, public conveyance, vessel, or bridge" [4]. Legal enforcement and trade secrets methods used to secure coupons [5]. The legal enforcement can be implemented using one or combination of patents, trademarks, registered designs, and others as copyright techniques. main while, the trade secrets can be implemented using formulas, process setting, secret materials and supply chains, and techniques. To implement coupons for fuel rationing system, the following security features are recommended. The first recommended security feature, is to use hidden Ultraviolet (UV) ink that is only visible under machines that have black light features, Figure 2 shows example of the hidden ink that is visible only on a special black light.

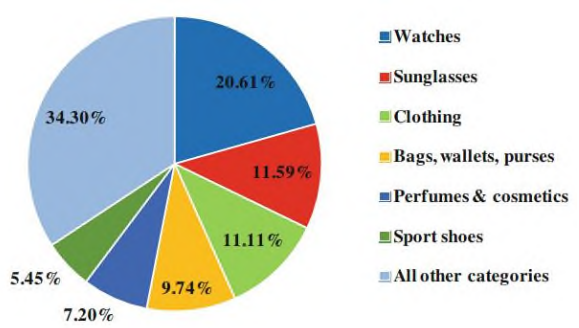

Figure 1: Counterfeit and pirated goods seized at the EU border (2013)

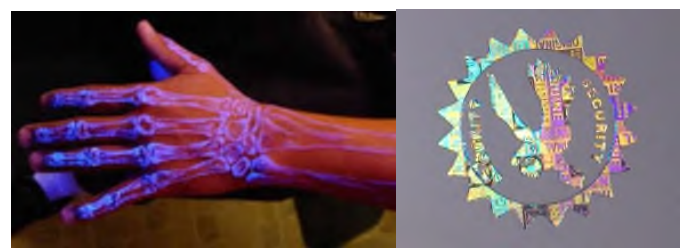

Figure 2: Hidden Ultraviolet (UV) ink visible by black light \& Foil Stamping Image Holograms

Secondly, is the Foil Stamping Image Holograms (see figure 2 at right side). To apply the image on the surface, rather than ink, foil stamping uses stamping foil and heat. Thirdly, is the coupon sequential numbering on both coupon stub as well as coupon body. Each ticket has the same content and a sequential number that increases by an increment of one each ticket. The usefulness of having a sequence number on each coupon is if there is a record of used tickets, the easier to detect the counterfeit coupons. Fourthly, is the Barcode technology which offers a several benefits (speed, accuracy, and less cost). When a laser from a barcode scanner scans the code, it's actually scanning a sequence of 95 evenly spaced 
columns. Computers only understand $1 \mathrm{~s}$ and 0 s, during scanning process, any columns that reflect no light is 1 , and the column that reflect a lot of light is 0 . The last recommended security feature, is the tamper-proof design. One way of using temper-proof design coupon is to have a part of coupon to be heat sensitive paper. Simply by worming the paper by device or rub it by hand, the ink on coupon will change colour to verify coupon authenticity. This method is a perfect for rapid authentication and can be used at big events as football matches or concerts.

\subsection{Counterfeiting Database (Cloud Database)}

Nowadays cloud computing and cloud services have gained much popularity. Several large and small size organisations prefer to outsource the information technology and database hosting services with several cloud service companies as Google and Microsoft. Advantages of outsourcing with cloud services are the company can focus on the core business rather than spend time and cost to manage databases and system security. However, privacy on using cloud services and data leakage are an open security problem. Several cloud computing threats could occur. They are data breaches, data loss, account or service traffic hijacking, insecure interfaces, denial of service, malicious insiders, abuse of cloud services, insufficient, and shared technology vulnerabilities. [6]. The main four concepts to be concerned when applying security in cloud. They are the software security, infrastructure security, storage security and network security.

\section{Secure Fuel Rationing System}

United Kingdom, several times suffered major fuel disruption, the major one was after the Arab Israel war in year 1973. The economic consequences of the fuel disruption were serious. This report demonstrates a secure solution by providing fuel rationing model to be used in case of short term crisis of a period of 14 day. The proposed model adapted from Daniel J. Bernny model in his book "Industrial Espionage" [7]. The steps of developing counterespionage program are three steps. First step is to start by conducting counterespionage risk assessment, second step is to develop the counterespionage plan, third step is to provide counterespionage awareness training. Here, we are adding step 4 is the damage control step, which is always considered when the organisation has a good leadership. Figure 3 shows the Gantt chart for the propose fuel rationing system.

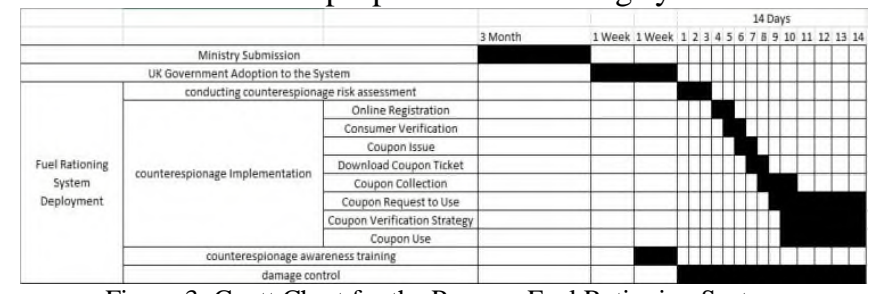

Figure 3: Gantt Chart for the Propose Fuel Rationing System

Proposed fuel rationing system quota is sown in table 1 . The quota is divided to two main consumer type, the individual and the group. Individual consumers are ordinary people who are a United Kingdom citizens or residence, who have a valid identification document, email, residence address, phone number, driving license, and owns or rent a vehicle. The proposed quota provides all types of consumers with the necessary amount of fuel to be used within one week period. There is no recommendation to have unlimited quota for any type, reason is, to control corruption. Special case consumers are individuals who have a job contributes a lot to the society, or people with special needs, as disabilities and pregnant women. Furthermore, organisations that contribute a lot to the society as hospitals, schools, and universities need to have more flexibility of the amount of fuel they use per a week.

3.1 Conducting a Counterespionage Risk Assessment Fuel shortage crisis is one of the major risk, to manage this risk, several international standards can be used as a guideline, some of them are, the Operationally Critical Threat, Asset, and Vulnerability Evaluation (OCTAVE ${ }^{\mathrm{SM}}$ ) that has three phases, they are build organisation security requirements, identify infrastructure vulnerabilities, and determine security risk management strategy [9]. One more standard is the American National Institute of Standards \& Technology (NIST) issued the Federal Information Processing Standards Publications (FIPS PUBS) [10]. The standard require implementation of the following: staff involvement, categorize the system, identify the threads, identify the vulnerability that could be exploited, identify controls, exploited likelihood, impact severity, and do the risk level. [11]. From the SWOT analysis, the strengths are the United Kingdom country has enough resources for implementation and the support by everyone in the country, the leadership and the people.

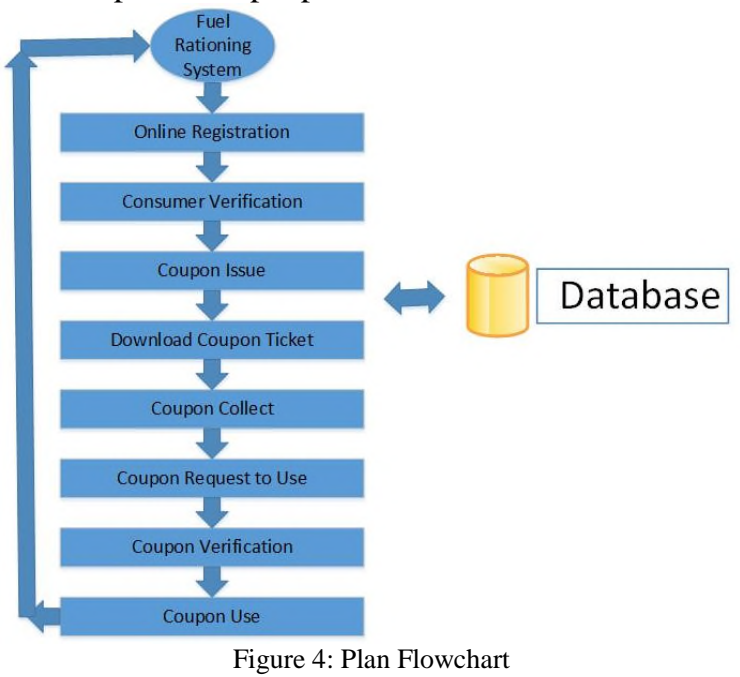

Opportunities are the new technology innovations and different methods to protect system from attacks counterfeiting as cryptography and latest internet security methods. The weakness can be found in the ability and intelligence of cyber attacker, furthermore the country has a high number of vehicle users that drives every day to works, schools, and shopping. There are approximately 9000 fuel stations in United Kingdom in year 2010 [12]. The most important threats of the rationing system are the corrupted people, since it's the human nature to have good and bad people in every nation, furthermore, the cyber security attack consider a major threat to the system. 
Table 1: Proposed Fuel Rationing System Quota

\begin{tabular}{|c|c|c|c|c|c|}
\hline \multicolumn{2}{|c|}{ Consumer Type } & Fuel Type * & $\begin{array}{l}\text { Price * } \\
\text { 08/01/17 }\end{array}$ & $\begin{array}{l}\text { Coupon } \\
\text { Category }\end{array}$ & $\begin{array}{l}\text { Ration Quota } \\
\text { Litre Per Week }\end{array}$ \\
\hline \multirow{10}{*}{ Individual } & \multirow{5}{*}{ Normal } & Unleaded & 118.66 & INU & 25 \\
\hline & & Diesel & 121.20 & IND & 30 \\
\hline & & Super Unleaded & 129.25 & INS & 25 \\
\hline & & Premium Diesel & 134.86 & INP & 30 \\
\hline & & LPG & 62.90 & INL & 30 \\
\hline & \multirow{5}{*}{ Special Case $* *$} & Unleaded & 118.66 & ISU & 50 \\
\hline & & Diesel & 121.20 & ISD & 60 \\
\hline & & Super Unleaded & 129.25 & ISS & 50 \\
\hline & & Premium Diesel & 134.86 & ISP & 60 \\
\hline & & LPG & 62.90 & ISL & 60 \\
\hline \multirow{10}{*}{ Group } & \multirow{5}{*}{$\begin{array}{c}\text { Government } \\
\text { and Police Vehicle }\end{array}$} & Unleaded & 118.66 & GGU & 75 \\
\hline & & Diesel & 121.20 & GGD & 90 \\
\hline & & Super Unleaded & 129.25 & GGS & 75 \\
\hline & & Premium Diesel & 134.86 & GGS & 90 \\
\hline & & LPG & 62.90 & GGL & 90 \\
\hline & \multirow{5}{*}{$\begin{array}{l}\text { Schools and } \\
\text { Hospitals }\end{array}$} & Unleaded & 118.66 & GSU & 75 \\
\hline & & Diesel & 121.20 & GSD & 90 \\
\hline & & Super Unleaded & 129.25 & GSS & 75 \\
\hline & & Premium Diesel & 134.86 & GSP & 90 \\
\hline & & LPG & 62.90 & GSL & 90 \\
\hline
\end{tabular}

* Source of United Kingdom fuel type and price www.petrolprices.com

**Special case could be Disability, Medical Doctors, Academicians, Pregnant Women Drivers.

\subsection{Develop Counterespionage Plan}

Figure 4 shows the proposed plan flowchart. The plan flowchart shows of the proposed rationing system with 8 subsequence stages and one main database. On stage 1 , the online registration, consumers need to have an internet and secure connection to connect to database server and fill the registration form. The online system can be accessed during days 4 and 5 . The first 3 days of the plan for conduct the risk assessment then the awareness and training process. During days 5 and 6 , the system employees to conduct the consumer verification stage. The employees are a special team from ministry of interior affairs, immigration department, and specialists on document verification. This team is to be given a special awareness and training program during days 1, 2, and 3. The training is about how to confirm originality of information provided by the consumers during online registration stage, and later during coupon verification stage. The coupon issuing stage, is after the consumer verification stage. The system will generate a softcopy ticket of type pdf, then send it online by email to the consumer. The ticket is not a coupon, it's a notification to collect coupon from the centre in the city. The consumer can download the ticket and keep it in mobile device to show it during the coupon collection step. After verification of the consumer online registration and tickets, the coupon hard copy to be provided to the consumer. Samples coupon is shown in Figure 5. The coupon can have some of the following features: coupon sequential numbering, Barcode, hidden Ultraviolet (UV) ink, and foil stamping image holograms. Furthermore, implementation of counterfeit deterrence system (CDS) on adobe products and other image editing software is recommended to prevent from printing or counterfeiting the coupons. At the fuel stations, a special Barcode reader and document verification device are used to verify the coupons. Samples of barcode reader and black light features device are shown in Figure 6. After coupon verification, the fuel amount listed in the coupon to be filled in the consumer vehicle. Now the consumer can benefit from the fuel rationing system during the period of the crisis.

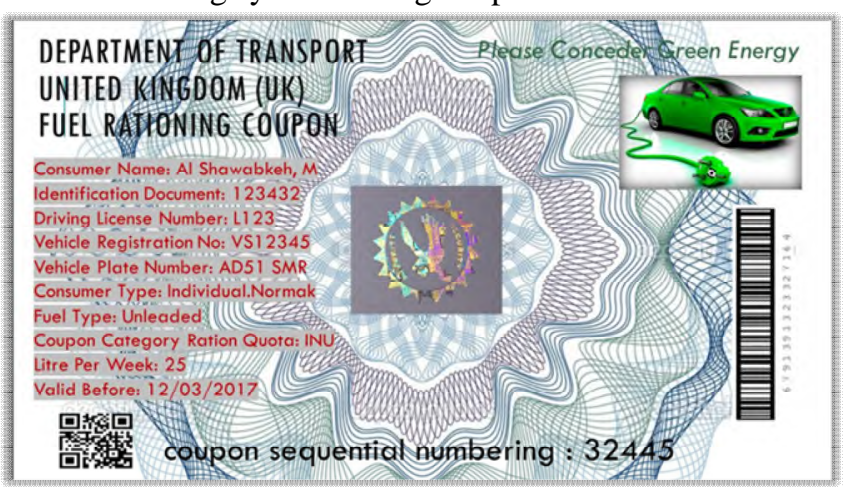

Figure 5: Coupon Sample for Fuel Rationing System
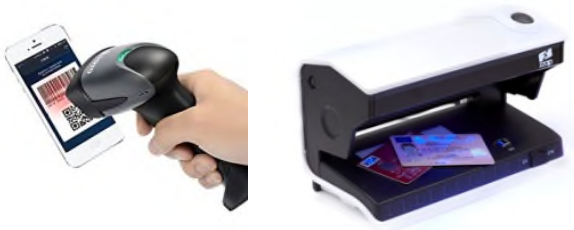

Figure 6: Barcode Reader and Black Light Features Device

\subsection{Counterfeiting System Database and System Security}

It is recommended to outsource the software and hardware of the system, reason is, the system is for temporary use, its less cost to rent the hardware by outsourcing rather than spent money on it. Furthermore, security employees need to be experts with high salary and demand lots of benefits, it's better to outsource the system to one of the reliable cloud provider. Microsoft cloud is a recommended choice (cloud.microsoft.com).

\subsection{Provide Counterespionage Awareness Training}

The step before counterespionage plan is the awareness and training. Training is very important, it's the way to provide 
employees with skills and knowledge required to implement the plan. Furthermore, ensuring that security officers at security department are trained effectively to meet the professionalism standard. Supervisors can monitor all employees and security officers and can guide them to implement the plan successfully. Furthermore, on-the-job training should be applied as well as online training using training websites. Not to forget the professional security certificates that can be obtained specially by the security officers. Document verification training need to be given to all fuel station employees. They must be professional in verifying the fuel coupon provided by the consumer to be not counterfeit copy. The process of making sure that the coupons presented by the consumer are genuine and the consumer is the rightful owner is called the document verification process [13].

\subsection{Damage Control}

Organization with good leadership knows that damage from risk always occur due to several reasons as worker's errors, outsider's disruption to the business, or company computer system and database failure. The leaders should always have a plan and be ready to handle the risk or the damage, or even prevent them from happening. Operational risk management plan (ORMP) is recommended to be initiated and implemented to can control the risk even before it happen.

\section{Main Three Effective Attacks}

The fuel rationing system is a huge project that require a lot of resources and man power. There are several vulnerabilities to the system, some of them are, the coupon counterfeiting, denial of service attack, and corruptions. The coupon counterfeiting vulnerability happen when attacker manage to print a similar coupon that makes process of document validity hard to detect the differences. The solution for this problem can be either one or combination of the following two methods. First the coupon design should have security features that make it difficult for the attacker to duplicate the coupons. For example, use hidden Ultraviolet (UV) ink and Foil Stamping Image Holograms. The second method is the use Counterfeit Deterrence System (CDS) that gives system error when printing a copy of the coupons on ordinary printers. The denial of service attack is a vulnerability on server that holds the software and database. This organised attack basically happens when lots of clients simultaneously request the same service from the server, that's makes the server busy all the time and cannot accept more connections from ordinary system users. The users keep trying to connect to the server but always get reply message that server is busy. There are several ways to prevent the denial of service attack, a basic one is to configure the server to reject connections from same client during a certain period of time. For the proposed fuel rationing system, we recommend to outsource the server services to cloud service provider as Microsoft cloud. The corruption problem is a human nature, this problem exists since the beginning of humanity on the earth. There are several ways to do with corruption rather than the punishments, we propose the use of leading change leadership method. The government to implement a large awareness program to inform people on the bad effect of corruption on society and economy. Especially, the government leaders need to be a model role for the society.

\section{Conclusion and Future Work}

The fuel rationing report presented in this project is explicitly introduce espionage and counterfeiting methods to prevent miss use of fuel as a major resource for transportation during crisis. The counterfeiting approach proposed in this project is focusing espionage and counterfeiting, including policies, techniques, tokens/coupons, and databases. project objectives achieved by proposing a 14-day fuel rationing system that is effective to use when crisis occur and risk become high. Future work and recommendation is to focus more on green technology to replace fuel as the main source of energy. The return on investment (ROI) on security such as physical security can improve financial return. Security professionals always try to explain the importance of system security to the top management but not easy to get funding approval. Future work can be done to discover ways to convince top management to invest more on the security and get the return. Lastly, the conclusions of this research can reveal useful to ministry of transport at United Kingdom by proving that usefulness of implementing the proposed rationing system during crisis

\section{References}

[1] A. Iosif and E. K. Fragkiskos, Industrial Espionage and Technical Surveillance Counter Measurers: Springer International Publishing 2016.

[2] Cambridge-Dictionary, "Counterfeiting Definition," ed, 2016.

[3] B. Ted, "Adobe Says It Uses Anti-Counterfeiting Technology " in Washington Post, ed, 01/10/2004.

[4] Counterfeiting and issuing of tokens, C. LAW § 8-612 (2015) 2015

[5] H. Duncan, "Module Materials: Industrial Espionage and Counterfeiting, IEC-WM05401MCS, 21st - 25th November 2016," ed: University of Warick, 2016.

[6] G. a.-M. Lorena, B. Gerd, and A. Matthias, An Architecture for Trusted PaaS Cloud Computing for Personal Data. Switzerland: Springer International Publishing 2014.

[7] J. B. Daniel, Industrail Espionage: Developing a Counterspionage Program: CRC Press, Taylor \& Francis Group, 2014.

[8] K. Brotby, Information security governance: a practical development and implementation approach: John Wiley \&amp;amp; Sons, 2009.

[9] C. J. Alberts, S. G. Behrens, R. D. Pethia, \&amp;amp, and W. R. Wilson, "Operationally Critical Threat, Asset, and Vulnerability EvaluationSM (OCTAVESM) Framework, Version 1.0 (CMU/SEI-99-TR-017)," in Pittsburgh, PA: Software Engineering Institute, ed. Carnegie Mellon University, 1999.

[10] FIPS-200, "FIPS Publication 200 Minimum Security Requirements for Federal Information and Information Systems," ed, 2006.

[11] mahmoud, "PMA: Information Risk Management And Governance (WM05501MCS)," University of Warwick2016.

[12] UKPIA, "UK Petroleum Industry Association Statistical Review," ed, 2010.

[13] Document-Verification, "A Good Practice Guide on PreEmployement Screening," Centre for the Protection of National Infrastructure (CPNI), United Kingdom2007. 